\title{
Tapirs in trouble: estimating Baird's tapir densities in the Sierra Madre de Chiapas, Mexico
}

\author{
Marina Rivero, J. Antonio de la Torre, Gamaliel Camacho \\ Eduardo J. Naranjo, Mathias W. Tobler, Christopher A. Jordan \\ Rodrigo A. Medellín and Rafael Reyna-Hurtado
}

\begin{abstract}
Spatial capture-recapture models have been widely used to estimate densities of species where individuals can be uniquely identified, but alternatives have been developed for estimation of densities for unmarked populations. In this study we used camera-trap records from 2018 to estimate densities of a species that does not always have individually identifiable marks, Baird's tapir Tapirus bairdii, in the Sierra Madre de Chiapas, southern Mexico. We compared the performance of the spatial capture-recapture model with spatial mark-resight and random encounter models. The density of Baird's tapir did not differ significantly between the three models. The estimate of density was highest using the random encounter model $\left(26 / 100 \mathrm{~km}^{2}, 95 \% \mathrm{CI} 12-41\right)$ and lowest using the capture-recapture model $\left(8 / 100 \mathrm{~km}^{2}\right.$, 95\% CI 4-16). The estimate from the spatial mark-resight model was 10/100 km² (95\% CI 8-14), which had the lowest coefficient of variation, indicating a higher precision than with the other models. Using a second set of camera-trap data, collected in 2015-2016, we created occupancy models and extrapolated density to areas with potential occupancy of Baird's tapir, to generate a population estimate for the whole Sierra Madre de Chiapas. Our findings indicate the need to strengthen, and possibly expand, the protected
\end{abstract}

MARINA RIVERO ${ }^{*}$ (Corresponding author, (D) orcid.org/0000-0002-8207-4171) EDGE of Existence Programme, Conservation and Policy, Zoological Society of London, London, UK. E-mail marinariverohdz@gmail.com

J. ANTONIO DE LA TORRE $\ddagger$ (iD) orcid.org/0000-0003-1994-8478) School of Environmental and Geographical Sciences, University of Nottingham Malaysia, Selangor, Malaysia

Gamaliel Camacho Tapires de la Sierra-Bioconciencia A.C., Mexico City, Mexico

Eduardo J. Naranjo (iD orcid.org/0000-0002-8680-8777) El Colegio de la Frontera Sur, San Cristobal de las Casas, Chiapas, Mexico

Mathias W. Tobler (1D orcid.org/0000-0002-8587-0560) San Diego Zoo, Global Institute for Conservation Research, Escondido, USA

Christopher A. Jordan (DD orcid.org/0000-0002-8498-6721) Global Wildlife Conservation, Austin, USA

Rodrigo A. Medellín ( (D) orcid.org/0000-0002-4242-5344) Instituto de Ecología, Universidad Nacional Autónoma de Mexico, Mexico City, Mexico

Rafael Reyna-Hurtado (iD orcid.org/0000-0003-4382-642X) El Colegio de la Frontera Sur, Campeche, Mexico

*Also at: Tapires de la Sierra-Bioconciencia A.C., Mexico City, Mexico

$\dagger$ Also at: El Colegio de la Frontera Sur, Campeche, Mexico

\$Also at: Jaguares de la Selva Maya-Bioconciencia A.C., Mexico City, Mexico

Received 10 January 2020. Revision requested 7 April 2020.

Accepted 13 October 2020. First published online 29 September 2021. areas of southern Mexico and to develop an action plan to ensure the conservation of Baird's tapir.

Keywords Density, Mexico, population size, random encounter model, Sierra Madre de Chiapas, spatial capturerecapture, spatial mark-resight, Tapirus bairdii

\section{Introduction}

Raird's tapir Tapirus bairdii is one of the last representa3 tives of the megafauna that survived Pleistocene extinctions and is considered a living fossil because of its unique morphological and behavioural characteristics, which resemble those of primitive ungulates (Janis, 1984). Tapirs are the largest native terrestrial mammals inhabiting the Neotropics (Naranjo, 2009), and because of their size and feeding habits they provide important ecosystem services as seed dispersers and seed predators and help shape forest succession via their selective browsing of seedlings (O'Farrill et al., 2013).

Historically, Baird's tapir ranged from south-east Mexico to north-west Colombia (García et al., 2016). It is now restricted to areas with large remnants of tropical forest (Schank et al., 2017). Populations are declining because of poaching, droughts and habitat loss caused by land-use change, and logging and fires (García et al., 2016). However, the extent of this decline is not well known because there is no reliable information on population density and size across most of the species' range (Naranjo, 2009; Mejía-Correa et al., 2010; González-Maya et al., 2012; Carbajal-Borges et al., 2014; Lavariega-Nolasco et al., 2016; Botello et al., 2017). With an estimated global total of c. 3,000 adults, Baird's tapir is categorized as Endangered on the IUCN Red List, (García et al., 2016), although variations in estimates (Naranjo, 2009; García et al., 2016; Schank et al., 2017) reflect uncertainty about the size of the population.

For estimating population and distribution parameters, including for elusive and unmarked species, camera trapping combined with density models is considered a robust tool (O'Connell et al., 2011). Three types of models have been developed. (1) The spatial capture-recapture model incorporates capture history information along with spatial information on where individuals were recorded (Efford et al., 2009; Royle et al., 2014). This model requires individual identification, which is problematic for species lacking individually identifiable markings (Rich et al., 2014). (2) Spatial 
mark-resight is a variation of the spatial mark-recapture model using individual encounter histories for animals that are marked and accumulated counts for unmarked individuals (Sollmann et al., 2013; Rich et al., 2014; Royle et al., 2014). (3) The random encounter model is an adaptation of gas collision theory, facilitating estimates of density without requiring identification of individuals, using the speed of movement of animals and sensor detection parameters of camera traps (Rowcliffe et al., 2008). These three types of model have been tested independently on a range of species (Sollmann et al., 2013; Cusack et al., 2015) but only a few studies have compared the effectiveness and applicability of these methodologies on the same population, especially for species that lack natural markings (Noss et al., 2012; Zero et al., 2013; Anile et al., 2014; Rich et al., 2014; Kane et al., 2015).

A related technique, occupancy models, have been widely used to make inferences regarding the factors influencing the distribution patterns of species (MacKenzie et al., 2006), estimating the probability that a species occurs in a particular area $(\psi)$ and its probability of detection (p), based on detection/non-detection histories obtained from repeat sampling (MacKenzie et al., 2006). The modelling of $\psi$ against covariates facilitates evaluation of which landscape variables are most strongly associated with a species' occupancy, and thus can be used to investigate species habitat preferences and create maps of potential distribution, to prioritize management and conservation efforts.

Here, we estimate the population size of Baird's tapir in the Sierra Madre de Chiapas using data from camera traps. We first compared the performance of the three density estimation models, and then used occupancy modelling to extrapolate density to areas with the highest probability of occurrence of the species and thus estimated the species' population in the Sierra Madre de Chiapas. Using these findings, we propose measures for the conservation of Baird's tapir in this region.

\section{Study area}

The Sierra Madre de Chiapas in southern Mexico is a rugged mountain range of c. 5,500 $\mathrm{km}^{2}$ at $200-2,900 \mathrm{~m}$ (CEIEG, 2010). It includes four protected areas: a State Reserve (Pico el Loro-Paxtal, $613 \mathrm{~km}^{2}$ ), and three federal protected areas (the Biosphere Reserves El Triunfo, $1,191 \mathrm{~km}^{2}$, and La Sepultura, 1,673 $\mathrm{km}^{2}$; and the Natural Resources Protected Area La Frailescana, $1,775 \mathrm{~km}^{2}$; Fig. 1). The landscape is a heterogeneous mosaic, with private and communal lands surrounding the protected areas. Land is used mainly for crop and livestock production, expansion of which continues to drive the agricultural frontier into forested areas. This habitat conversion, along with subsistence hunting and fires, are the main threats to wildlife in the region, especially for tapirs and other large mammals (Naranjo, 2009).

\section{Methods}

\section{Density}

We conducted a camera-trap survey in La Frailescana during April-July 2018, with a total of 58 camera-trap stations (48 with two cameras and 10 with single cameras). Camera-trap stations where in two contiguous blocks of 29 camera-trap stations each, over a total area of $70 \mathrm{~km}^{2}$ (Fig. 1). The first block was active during April-May 2018 and the second block during May-July 2018. Sampling effort was 2,975 camera-days and stations were active $53 \pm \mathrm{SE} 2$ days to ensure demographic closure. Stations were a mean distance of $813 \pm$ SE $227 \mathrm{~m}$ apart, and installed c. $50 \mathrm{~cm}$ above the ground.

We calculated tapir density estimates using spatial capture-recapture, spatial mark-resight, and the random encounter models. Spatial capture-recapture models consider that each individual of the population has an activity center $(s)$ around which the movements of that individual are concentrated. This model estimates density by modeling the number and location of the individuals' activity centers $s_{i}$ within the space state $\mathrm{S}$. Therefore, encounter probability is modeled as a function of the distance between camera traps and the individual activity center. The model requires that all photographed individuals be identified. All tapir photographs obtained from the camera-trap survey were analysed to identify tapir individuals from unique marks such as spots, scars, notches on the ears, body structure and sex (González-Maya et al., 2012). Tapir images that could not be assigned to an individual were discarded for the spatial capture-recapture analysis, but were included as unmarked individuals for the spatial mark-resight analysis. To improve the accuracy of individual identification, we used the methodology of Foster \& Harmsen (2012), in which two researchers independently classified all tapir individuals and then compared results to reach a consensus.

We analysed our data with a maximum-likelihood spatial capture-recapture model (Efford et al., 2009) using the package secr 3.2.o (Efford, 2020) in $R$ 3.5.1 (R Core Team, 2018). We defined our state-space as the size of the camera array polygon plus a buffer of $2.3 \mathrm{~km}$; this distance was chosen based on the theory that the buffer should be wide enough to have zero probability that animals present at the edge appear in our sample (Efford et al., 2009). Spatial capture-recapture models allow for variation in parameters related to the detection probability, but for the purposes of this study we assumed that detection probabilities were the same. We fitted the model using a half-normal detection function with a Poisson distribution (Efford, 2020). We used the same parameter values for the spatial mark-resight model, to facilitate comparison.

We implemented the spatial mark-resight model by using encounter history data from marked individuals and counts of unmarked individuals. In this model, sampling 


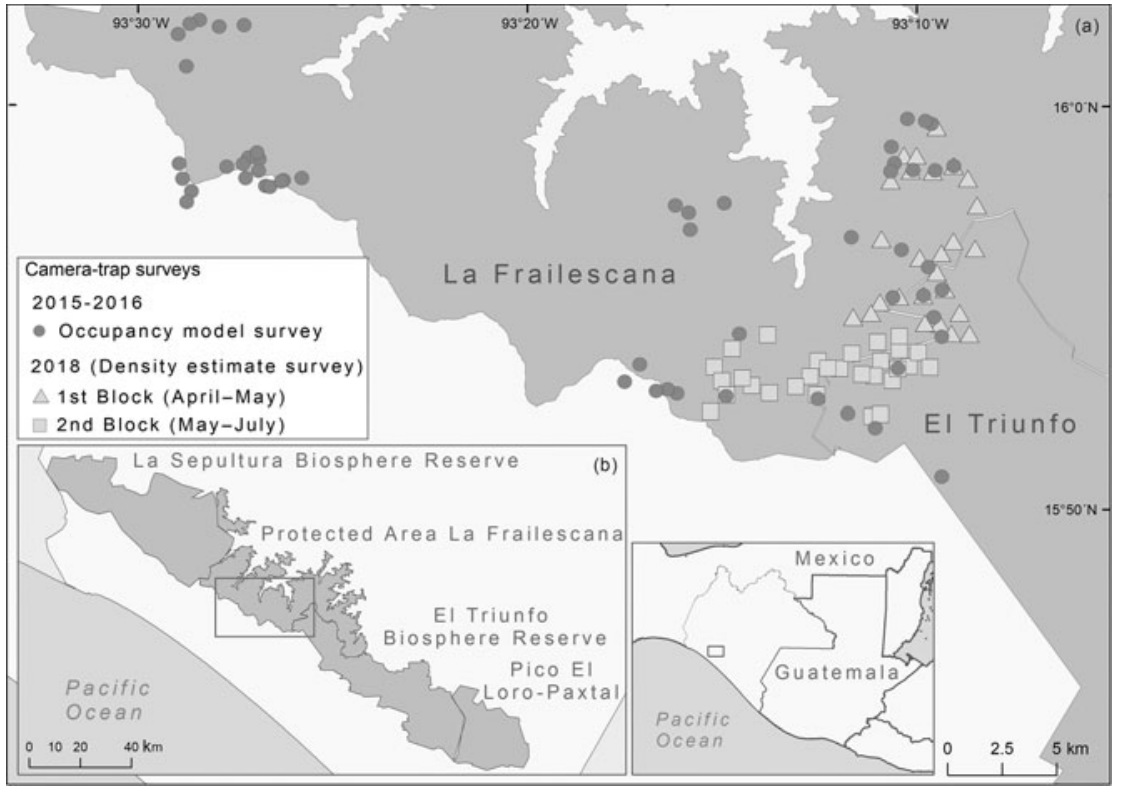

FIG. 1 (a) Camera-trap stations used in 2015-2016 and 2018 in the Natural Resources Protected Area La Frailescana in the Sierra Madre de Chiapas, Mexico for Baird's tapir Tapirus bairdii. (b) The Sierra Madre de Chiapas, showing the four protected areas. events are either marking or sighting occasions (Efford, 2020). We used the sighting-only model with the number of marked animals at the time of sampling unknown, using function addSightings and the attributes markocc and $T u$ in secr. We used the same buffer size and input files as for the spatial capture-recapture models but with an additional capture history data set, which included counts of unmarked animals in binary form (1/o). For the counts dataset, images where only parts of the individual were visible were discarded and we did not use temporary marks such as dermal parasites or physical condition, to avoid misidentification of marked and unmarked individuals. We used the half-normal detection function to fit the model. Because of the overdispersion of the counts, we re-fitted the model using an overdispersion-adjusted pseudo-likelihood (Efford, 2020).

The random encounter model (Rowcliffe et al., 2008) uses information from the camera-trap detection zone, and the species' encounter rate and speed of movement. This model estimates density $(D)$ using:

$$
D=\frac{y \quad \pi}{t(v r(2+\theta))}
$$

where $y=$ number of independent tapir detections, $t=$ survey effort (in days), $v=$ speed of movement $(\mathrm{km} /$ day), $r=$ radial distance to the animal (in $\mathrm{m}$ ), and $\theta=$ zone of detection (in radians).

We defined independent detections as photographs of Baird's tapir separated by at least $24 \mathrm{~h}$ (Lavariega-Nolasco et al., 2016). Ideally, $v$ is estimated at the same time and place as the camera-trap survey (Rowcliffe et al., 2008). However, as speed of movement data were not available for Baird's tapir at the study site, we used data for Baird's tapir in Indio Maíz, Nicaragua (Jordan et al., 2019), for
Tapirus pinchaque in the Central Andes, Colombia (Lizcano \& Cavelier, 2004), and for Tapirus terrestris in Madre de Dios, Peru (Tobler, 2008). Based on the mean speed of the three species and on expert judgment (M. Tobler, pers. comm., 2018), we used $6 \mathrm{~km} /$ day for $v$. Detection zone parameters, $r$ and $\theta$, were calculated by performing measurements for each camera trap. We ran the random encounter model using 10,000 bootstraps in camtools 1.0 for $R$ (Rowcliffe, 2019).

For each density estimate, we calculated the coefficient of variation as a measure of precision (White et al., 1982). We compared the three models using the $95 \%$ confidence intervals, considering estimates to be significantly different if the confidence intervals did not overlap.

\section{Occupancy}

We used likelihood-based occupancy modelling to identify variables that best explain occupancy and detectability in the Sierra Madre de Chiapas. We used the framework and camera-trap data of de la Torre et al. (2018), also from Sierra Madre de Chiapas, as these data were from a greater number of sites. Camera trapping took place during August 2015-December 2016, with 55 camera-trap stations over $400 \mathrm{~km}^{2}$ in La Frailescana (Fig. 1). Sampling effort was 9,274 trap-days and stations were active from 34 days to 15 months.

We compiled 12 covariates to model occupancy and detection probabilities for Baird's tapir (Table 1). We generated raster layers with pixels of $30 \times 30 \mathrm{~m}$ resolution and used circular moving window radii of $30,90,240,510$, and $1,020 \mathrm{~m}$ to evaluate the most informative scale for analysis. We developed detection/non-detection histories based on photographic records, using 15 -day sampling periods to 
TABLE 1 The 12 covariates used to model occurrence $(\psi)$ and detectability (p) of Baird's tapir Tapirus bairdii in the Sierra Madre de Chiapas, Mexico.

\begin{tabular}{|c|c|c|c|}
\hline Variable name (by type) & Abbreviation & $\begin{array}{l}\text { Expected } \\
\text { result }\end{array}$ & Hypothesis \\
\hline \multicolumn{4}{|l|}{ Forest cover } \\
\hline Forest cover & $\mathrm{C}$ & $\beta>0$ & \multirow{3}{*}{$\begin{array}{l}\text { Baird's tapir is restricted mostly to areas with primary forest (Tobler, 2002; } \\
\text { Naranjo, 2009). }\end{array}$} \\
\hline $\begin{array}{l}\text { Primary forest } \\
\quad(>75 \% \text { of forest cover })\end{array}$ & P For 75 & $\beta>0$ & \\
\hline $\begin{array}{l}\text { Primary forest } \\
\qquad(>90 \% \text { of forest cover })\end{array}$ & P For 90 & $\beta>0$ & \\
\hline \multicolumn{4}{|l|}{ Terrain } \\
\hline Elevation & ELE & $\beta>0$ & \multirow{4}{*}{$\begin{array}{l}\text { Upper mountain habitats with greater topographic complexity could be } \\
\text { more suitable for Baird's tapir as low \& middle elevations have more hunting } \\
\text { \& more deforestation (González-Maya et al., 2012; de la Torre et al., 2018). }\end{array}$} \\
\hline Shannon topographic index & SHA & $\beta>0$ & \\
\hline Topographic position index & TPI & $\beta>0$ & \\
\hline \multicolumn{3}{|l|}{ Human influence } & \\
\hline Distance to towns & Dist T & $\beta>0$ & \multirow{4}{*}{$\begin{array}{l}\text { Persecution of Baird's tapir \& habitat destruction by human activities affects } \\
\text { occurrence (Naranjo, 2009). }\end{array}$} \\
\hline Distance to paved roads & DistR & $\beta>0$ & \\
\hline Distance to deforestation edge & $\mathrm{DE}$ & $\beta>0$ & \\
\hline Density of towns & DENT & $\beta>0$ & \\
\hline \multicolumn{4}{|l|}{ Site covariates ${ }^{1}$} \\
\hline Season & SEASON & $\beta>0$ & $\begin{array}{l}\text { Detectability is greater in dry season, when home range increases (Foerster } \\
\text { \& Vaughan, 2002). }\end{array}$ \\
\hline Sampling effort & EFFORT & $\beta>0$ & Increasing sampling effort increases detectability (de la Torre et al., 2018). \\
\hline
\end{tabular}

${ }^{1}$ Only for modelling detectability.

increase detection probability as Baird's tapir can move its home range every 10-12 days (Jordan, 2015). We extracted values of each covariate from the location of the camera trap and rescaled them using the mean value for each covariate divided by the standard deviation. We compared all variables with a Pearson test for multicollinearity and we did not include in the same model variables correlated at $>0.6$.

Detection and occupancy probabilities were estimated on 35 sampling occasions following a single season model, assuming a closed population and constant tapir occupancy throughout the sampling period (MacKenzie et al., 2006). We fitted occupancy models in the package Unmarked 3.1.1 for $R$ (Fiske et al., 2011), using the logit link function and 2,00o bootstraps to assess the adjustment fit (P). We compared models using Akaike information criterion (AIC) scores and weights, and we only considered models with $\Delta \mathrm{AIC} \leq 2$ (Burnham \& Anderson, 2004).

We evaluated the accuracy of our best candidate model by calculating the area under the receiver operator characteristic (ROC) curve, which is obtained by plotting sensitivity (number of true positive predictions) vs 1 - specificity (number of false positives; Manel et al., 2001). This measures the model's ability to correctly determine which locations are occupied. Usually, values of $\leq 0.5$ indicate that the model performs no better than random. Values $>0.5$ indicate progressively better discrimination (Manel et al., 2001). We also determined the optimal threshold value with $95 \%$ confidence intervals for categorizing continuous occupancy values as potential habitat and non-habitat (Liu et al., 2005). To have a more robust estimate of the potential habitat for the species in the region, we defined occupancy probabilities greater than the upper confidence interval of the optimal threshold value as potential habitat, and areas below the upper confidence interval of the optimal threshold value as non-habitat. We used the $R$ package $p R O C$ (Robin et al., 2011), and a database of 58 Baird's tapir records from the region (observations of footprints and scats; CONABIO, 2020), and generated 800 random points as pseudo-presences for the analysis.

To calculate tapir occupancy probability in each cell of $30 \times 30 \mathrm{~m}$, we used the inverse logit function, applying the information of the best occupancy model in the Raster Calculator tool of ArcGIS 10.2 (Esri, Redlands, USA). We used forest cover $>75 \%$ as a data mask to extract values of the occupancy raster. We grouped occupancy probability values into three categories: (1) low occupancy: from the upper confidence interval of the optimal threshold value to 0.59 ; (2) medium occupancy: 0.6-0.89; and (3) high occupancy: 0.9-1.0. We converted the raster into polygons and calculated the surface area of each classification. To estimate the population size of Baird's tapir in the Sierra Madre de Chiapas, we extrapolated density estimates using the mean density of each model and extrapolated to each interval.

\section{Results}

Density We obtained 426 photographs of Baird's tapir. Of these, 38 were independent records, separated by more than $24 \mathrm{~h}$, with a capture rate of 1.3 photographs/10o camera days. 
We identified eight adult individuals and there were nine independent records that could not be assigned to an identified individual. The estimated density was 8 individuals/ $100 \mathrm{~km}^{2}$ (95\% CI 4-16) with the spatial capture-recapture model, 10 individuals $/ 100 \mathrm{~km}^{2}$ ( $95 \%$ CI 8-14) with the spatial mark-resight model, and 26 individuals $/ 100 \mathrm{~km}^{2}$ (95\% CI 1342) with the random encounter model. Spatial mark-resight had the lowest coefficient of variation, indicating a better precision compared to the other models (Table 2).

Occupancy The data of de la Torre et al. (2018) contained 154 independent records of Baird's tapir. The species was detected at 25 of the 55 sampling sites, giving a naïve occupancy estimate of 0.45 . The best model (i.e. with the lowest $\triangle \mathrm{AIC}$ Table 3) suggested that tapir occupancy increased with elevation (ELE1020 $\beta$ 0.99, 95\% CI o.16-2.1) and greater topographic heterogeneity (SHA240 $\beta$ 2.78, 95\% CI 0.99-5.2). Detection probability also increased at higher elevations (ELE9o $\beta$ 0.53, 95\% CI 0.19-0.88), at greater distances from deforested patches (DE9o $\beta$ 0.56, 95\% CI 0.23-0.89) and when sampling effort was greater (EFFORT $\beta$ o.16, 95\% CI 0.07-0.26). Our results suggest that Baird's tapir is associated with higher elevations and rugged terrain, landscapes that are found in the most remote areas of the Sierra Madre de Chiapas, where human presence is scarce or limited (for more details, see de la Torre et al., 2018). The area under the ROC curve for our best occupancy model was 0.79 ( $95 \%$ CI $0.75-0.84$ ), meaning that it can be considered to have good discriminatory ability (Pearce \& Ferrier, 2000). The model correctly predicted occupied sites (sensitivity $0.83,95 \% \mathrm{CI}$ $0.72-0.97$ ) better than unoccupied sites (specificity 0.69 , 95\% CI 0.52-0.78). The optimum threshold value to discriminate Baird's tapir habitat from non-habitat was 0.02 (95\% CI 0.01-0.2).

Population size in the Sierra Madre de Chiapas Using the model that best described tapir occupancy, we estimated that the area of occurrence of Baird's tapir in the Sierra Madre de Chiapas encompassed a maximum area of $2,305 \mathrm{~km}^{2}$ (considering all three occupancy intervals; Fig. 2). Considering medium and high occupancy intervals $\left(1,660 \mathrm{~km}^{2}\right)$ combined with the density estimate from the spatial mark-resight model (i.e. the model with the best precision), we obtained a population size of 166 (95\% CI 133-232) individuals; and using the three occupancy intervals $\left(2,305 \mathrm{~km}^{2}\right), 231(95 \%$ CI 184-323) tapir individuals for the entire region (Table 4).

\section{Discussion}

\section{Estimating density}

As far as we are aware, this is the first study to estimate the density of Baird's tapir from camera-trap data using two spatially explicit models and the random encounter model. Although we do not have a complete census of this tapir in the Sierra Madre de Chiapas with which to compare our estimates from the three models, our findings suggest the spatial mark-resight model produced the most precise density estimate. The three models have overlapping 95\% confidence intervals, indicating no significant differences between them. However, the estimate of density from the spatial capture-recapture model was one of the lowest across the species' range (Table 5).

Although the low density of Baird's tapir in the Sierra Madre de Chiapas may be a result of poaching and habitat loss (de la Torre et al., 2018), the large variations in density estimated in previous studies may be related to data quality and methods of data analysis. For example, some studies that used capture-recapture models and resulted in the highest density values (Mejía-Correa et al., 2010; GonzálezMaya et al., 2012; Botello et al., 2017) deployed $\leq 10$ camera trap stations, with an effective sampling area of $7-19 \mathrm{~km}^{2}$ estimated from $1 / 2$ mean maximum distance moved (Table 5 ). This approach is now known to overestimate density because spatial information related to home range and movement obtained from camera-trap locations is not adequately integrated into modeling (Noss et al., 2012; Tobler \& Powell, 2013). Moreover, to obtain a reliable density estimate, camera-trap polygons should be several times larger than the average home range of the target species, and have sufficient camera-trap stations to ensure recaptures of multiple individuals at multiple stations (Noss et al., 2012).

For the random encounter model, we obtained a coefficient of variation of $28 \%$, which indicates a low precision (White et al., 1982). This may be because camera-trap locations were not chosen randomly as a result of the rugged terrain, and the speed of movement parameter was not available for our study site, potentially introducing additional bias as the model depends on the reliability of this parameter (Rowcliffe et al., 2008; Cusack et al., 2015).

Spatially explicit models have proven to be effective for estimating the density of species with individually identifiable markings, and of unmarked animals (Anile et al., 2014; Rich et al., 2014; Kane et al., 2015). In our study, even though the two spatially explicit models gave similar results, spatial mark-resight produced a slightly higher density estimate with a coefficient of variation of $15.4 \%$, in contrast to $37 \%$ for the spatial capture-recapture model (White et al., 1982). Differences in estimation and precision between models are likely because spatial mark-resight uses both the encounter data from the marked individuals, which provides movement and detection information, and the count data of unmarked individuals (Royle et al., 2014). The latter helps to improve density estimates that would otherwise be biased by removing a large proportion of photographs that cannot be attributed to individuals (Chandler \& Royle, 2013). 
TABLE 2 Summaries of the spatial capture-recapture, spatial mark-resight and random encounter models for estimating the density of Baird's tapir using data from camera trapping in the Sierra Madre de Chiapas during April-July 2018.

\begin{tabular}{|c|c|c|c|c|}
\hline Model & Density \pm SE $\left(\right.$ per $\left.100 \mathrm{~km}^{2}\right)$ & $\mathrm{g} 0 \pm \mathrm{SE}^{1}$ & Sigma $\pm \mathrm{SE}^{2}$ & $\mathrm{CV}(\%)^{3}$ \\
\hline Spatial capture-recapture & $8 \pm 3.0$ & $0.04 \pm 0.01$ & $655 \pm 77.9$ & 37.0 \\
\hline Spatial mark-resight & $11 \pm 1.7$ & $0.04 \pm 0.01$ & $654 \pm 77.5$ & 15.4 \\
\hline Random encounter & $26 \pm 7.4$ & & & 28.0 \\
\hline
\end{tabular}

${ }^{1}$ Magnitude of detection function.

${ }^{2}$ Spatial scale of detection function (m).

${ }^{3}$ Coefficient of variation calculated as $\mathrm{SE}[D] / D \times 100$.

TABLE 3 Occupancy $(\psi)$ and detection (p) models for Baird's tapir, based on data from camera trapping in the Sierra Madre de Chiapas during August 2015-December 2016 (de la Torre et al., 2018).

\begin{tabular}{|c|c|c|c|}
\hline Model $^{1}$ & $\mathrm{AIC}^{2}$ & $\Delta \mathrm{AIC}^{3}$ & $w_{i}^{4}$ \\
\hline $\begin{array}{l}\psi(\text { SHA240 + ELE1020) } \\
\quad \text { p(DE90 + ELE90 + EFFORT })\end{array}$ & 506.00 & 0.00 & 0.33 \\
\hline $\begin{array}{l}\psi(\text { SHA240 + ELE1020 + PFor75_510 }) \\
\text { p(DE90 + ELE90 + EFFORT })\end{array}$ & 508.50 & 2.48 & 0.10 \\
\hline $\begin{array}{c}\psi(\text { SHA240 + ELE1020 + C1020 }) \\
\text { p }(\text { DE90 + ELE90 + EFFORT })\end{array}$ & 508.60 & 2.61 & 0.09 \\
\hline $\begin{array}{l}\psi(\text { SHA240 }) \\
\quad \text { p(DE90 + ELE90 + EFFORT })\end{array}$ & 509.00 & 2.99 & 0.08 \\
\hline $\begin{array}{l}\psi(\text { SHA240 + C1020) } \\
\quad \text { p }(\text { DE } 90+\text { ELE } 90+\text { EFFORT })\end{array}$ & 509.40 & 3.47 & 0.06 \\
\hline$\psi(.) ; \mathrm{p}()$. & 588.10 & 82.08 & 0.001 \\
\hline
\end{tabular}

${ }^{1}$ Numbers after the variable represent the window area radii $(90,240,510$, $1,020 \mathrm{~m}$ ) and (.) is a constant.

${ }^{2}$ Akaike information criterion.

${ }^{3} \triangle \mathrm{AIC}$, difference in AIC from best-performing model.

${ }^{4} w_{i}$, Akaike weight.

Previous studies have also shown that, compared to other models, the spatial mark-resight model improves density estimates for species without individually identifiable markings (Rich et al., 2014; Kane et al., 2015), and simulations have shown that estimates from the spatial mark-resight model are more precise and less biased than those using only marked individuals (Chandler \& Royle, 2013). Nevertheless, there are some potential limitations arising from the assumptions of the spatial mark-resight model (no marks are lost between marking and resighting, and all individuals are correctly identified as marked or unmarked; Royle et al., 2014), especially when using camera traps. Both assumptions may be violated if blurred photographic records or temporary marks are used. Other limitations are the time required to identify individuals and uncertainty associated with identification. However, several studies on tapirs have shown consistency between researchers in the number of individuals identified, and identification can be improved when results are discussed among researchers, to reach a consensus (González-Maya et al., 2012; Tobler et al., 2013). We attempted to ensure that we met these assumptions and performed individual identification as accurately and conservatively as possible. Although the model needs to be improved (Chandler \& Royle, 2013; Royle et al., 2014), spatial mark-resight can address many of the problems of estimating the population density of species that may not always have individually identifiable marks.

\section{Population size in the Sierra Madre de Chiapas}

Considering only the medium and high occupancy intervals $\left(1,660 \mathrm{~km}^{2}\right)$ and using the density estimated by the spatial mark-resight model, our estimate of a population size of 166 (95\% CI 133-232) Baird's tapirs in the Sierra Madre de Chiapas is lower than the 225 individuals estimated by Naranjo (2009) for the same region and a similar area $\left(1,500 \mathrm{~km}^{2}\right)$. If we include the lower occupancy interval $\left(645 \mathrm{~km}^{2}\right)$, our estimate of population size increases to 230 (95\% CI 184-323). However, areas with lower occupancy must be considered cautiously, as occurrence probability is $<60 \%$, and these areas are closer to towns, roads, livestock and agricultural lands, which limit tapir presence. Although any extrapolation should be considered cautiously, we were confident to extrapolate our estimates of density to the whole Sierra Madre de Chiapas landscape because its characteristics (rugged and mountainous terrain, vegetation types, climate, social context, and threats to Baird's tapirs; Naranjo, 2009) are similar to those of the area where we set camera traps.

\section{Conservation implications}

The Sierra Madre de Chiapas harbours one of the six remaining Baird's tapir populations in Mexico, and the area is critical for maintaining connectivity with the populations of El Ocote in Chiapas and Chimalapas in Oaxaca (de la Torre et al., 2018; Schank et al., 2020). Our findings support the need to strengthen the four protected areas of the Sierra Madre de Chiapas. A comparison of our findings with those of Naranjo (2009) suggest the tapir population in the Sierra Madre de Chiapas could have declined by c. $30 \%$ in the last 10 years. Poaching is a severe threat to Baird's tapir in this region (Naranjo, 2009; de la Torre 


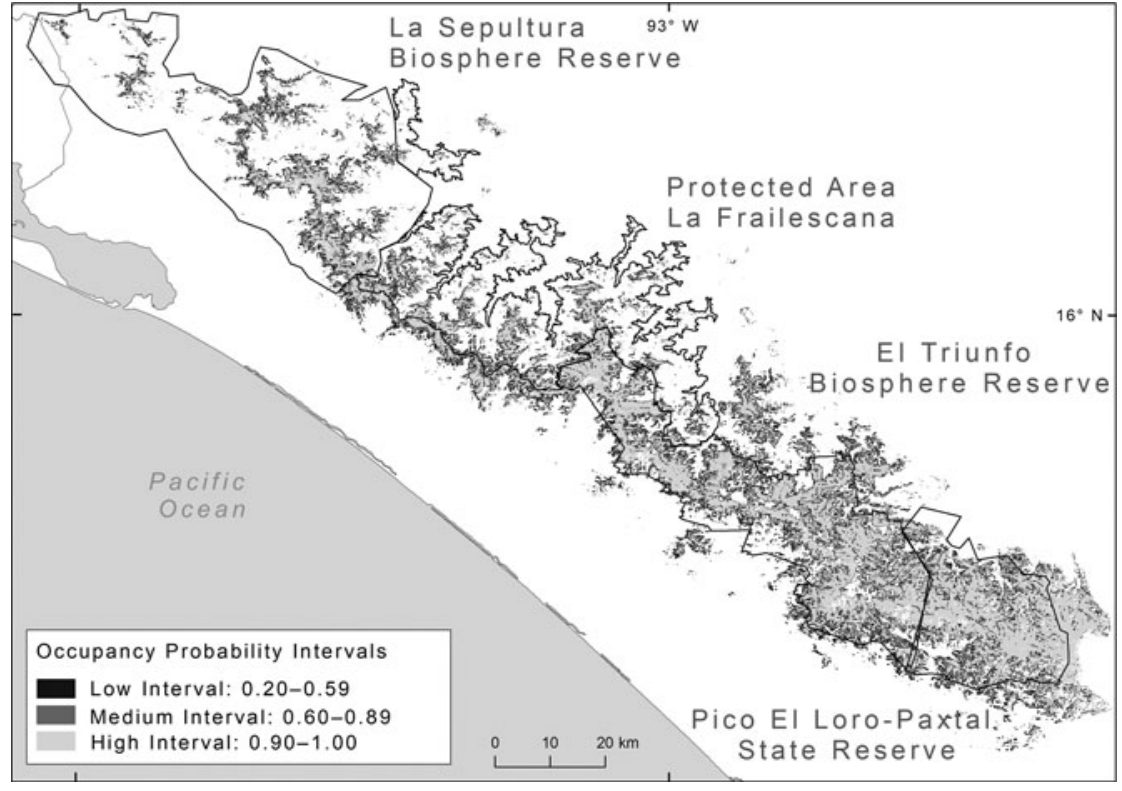

Fig. 2 Probability of occupancy of Baird's tapir in the Sierra Madre de Chiapas, classified in areas of low, medium and high occupancy.

TABLE 4 The number of Baird's tapir in the Sierra Madre de Chiapas estimated for each occupancy interval, based on the mean density estimated by the spatial capture-recapture, spatial mark-resight and random encounter models.

\begin{tabular}{lclcl}
\hline Occupancy interval & Area $\left(\mathrm{km}^{2}\right)$ & \multicolumn{4}{l}{ Number of individuals $(95 \% \mathrm{CI})$} & \\
\hline & & Capture-recapture & Mark-resight $^{2}$ & Random encounter $^{3}$ \\
Low $(0.20-0.59)$ & 645 & $52(26-103)$ & $65(52-90)$ & $168(77-264)$ \\
Medium $(0.60-0.89)$ & 622 & $50(25-100)$ & $62(50-87)$ & $162(75-255)$ \\
High $(0.90-1.00)$ & 1,038 & $83(42-166)$ & $104(83-145)$ & $270(125-426)$ \\
\hline
\end{tabular}

${ }^{1} 8$ individuals $/ 100 \mathrm{~km}^{2}$ (95\% CI 4-16).

${ }^{2} 10$ individuals $/ 100 \mathrm{~km}^{2}$ (95\% CI 8-14).

${ }_{2}^{3} 6$ individuals $/ 100 \mathrm{~km}^{2}$ (95\% CI 12-41).

et al., 2018), and we therefore recommend that La Frailescana be given a higher category of protection (e.g. Biosphere Reserve), as it is located between two existing Biosphere Reserves (El Triunfo and La Sepultura) and it is crucial to maintain the connectivity and integrity of the entire Sierra Madre de Chiapas landscape.

If not addressed, the debilitation of the Commission of Protected Areas by past and current administrations, including the dismissal of park rangers and other personnel and decreases in conservation budgets, will potentially result in the loss of genetic connectivity for Baird's tapirs and other species in the Sierra Madre de Chiapas. Any further loss of connectivity and increase in habitat fragmentation could lead to the extirpation of threatened and emblematic species from this region, including Baird's tapir and the jaguar Panthera onca. If the tapir metapopulation in Mexico is to remain viable, there needs to be investment in the establishment of additional habitat for the species, including through schemes such as payments for ecosystem services on communal and private lands (de la Torre et al., 2018; Schank et al., 2020). For the Sierra Madre de Chiapas, we encourage the government to add national lands to existing protected areas, to increase their size and prevent further habitat degradation and deforestation. To contribute to these strategies, future research on tapirs in the Sierra Madre de Chiapas should focus on surveying areas for which there is no information, such as Pico El Loro-Paxtal State Reserve, and unprotected areas that hold potential value as genetic corridor habitat (Schank et al., 2020).

Moreover, it will be critical to integrate local communities in decision-making to ensure that strategies and conservation actions for Baird's tapir have their support. Within communal lands, other conservation strategies will also be necessary, including participatory management and land-use planning to identify and prioritize conservation areas and actions for Baird's tapirs on communal lands. Fostering alternative sustainable livelihoods such as ecotourism and agroforestry systems can alleviate and reduce the impact of poaching and habitat loss in the region and in turn promote the improvement of livelihoods and the conservation of habitat for Baird's tapir (Cove et al., 2013). Ultimately the only way to ensure Baird's tapir conservation 


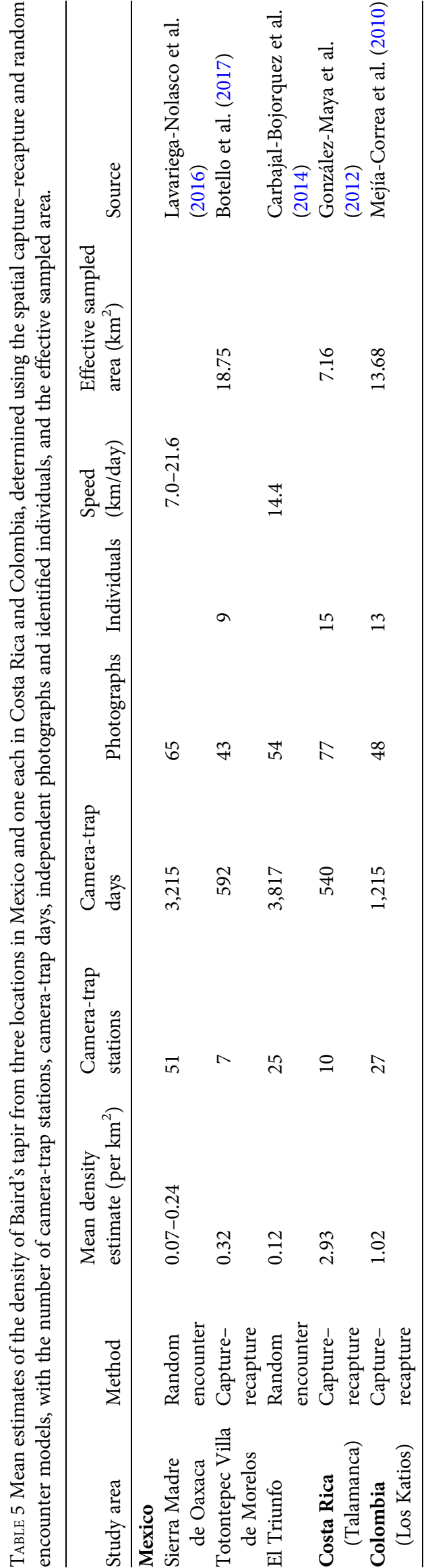

in the Sierra Madre de Chiapas is for local and federal government institutions, NGOs and local communities to collaborate in ways that allow them to strengthen protected areas and promote the development of sustainable alternatives to livestock production and other extensive agricultural systems, to facilitate the coexistence of tapirs and local communities.

Acknowledgements MR acknowledges the scholarship and financial support provided by Consejo Nacional de Ciencia y Tecnología (624549) and El Colegio de la Frontera Sur. We thank the administration of the Natural Resources Protected Area La Frailescana (Comisión Nacional de Áreas Naturales Protegidas, particularly R. DiazVelazquez and M. Morales-Hernandez, for supporting this research; the communities of Plan de Ayala, Reforma-Agraria, FranciscoMurguía and Joaquín Miguel-Gutierrez, and especially the community monitors, and Itzamná Guarneros and Leonardo Díaz, for field assistance; Paulina Arroyo for help with tapir identification; Ninon Meyer for comments on the text; and two anonymous reviewers for their helpful critiques. This work was financed by the Zoological Society of London EDGE of Existence Programme-National Geographic Photo Ark and Wildlife Conservation Network.

Author contributions Conceptualization: MR; study design: MR, JAdlT, RR-H, MWT, EJN; compilation of data, setting camera traps: MR, JAT, GC; writing: MR, assisted by JAdlT, RR-H, MWT, EJN, CAJ, RAM.

Conflicts of interest None.

Ethical standards This research abided by the Oryx guidelines on ethical standards.

\section{References}

Anile, S., Ragni, B., Randi, E., Mattucci, F. \& Rovero, F. (2014) Wildcat population density on the Etna volcano, Italy: a comparison of density estimation methods. Journal of Zoology, 293, 252-261.

Botello, F., Romero-Calderón, A.G., Sánchez-Hernández, J., Hernández, O., López-Villegas, G. \& Sánchez-Cordero, V. (2017) Densidad poblacional del tapir centroamericano (Tapirella bairdii) en bosque mesófilo de montaña en Totontepec Villa de Morelos, Oaxaca, México. Revista Mexicana de Biodiversidad, 88, 918-923.

Burnham, K.P. \& Anderson, D.R. (2004) Multimodel inference: understanding AIC and BIC in model selection. Sociological Methods \& Research, 33, 261-304.

Carbajal-Borges, J.P., Godínez-Gómez, O. \& Mendoza, E. (2014) Density, abundance and activity patterns of the Endangered Tapirus bairdii in one of its last strongholds in southern Mexico. Tropical Conservation Science, 7, 100-114.

CEIEG (2010) Región VI. Frailesca. Comité Estatal de Información Estadística y Geográfica de Chiapas, Gobierno del Estado de Chiapas, Tuxtla Gutiérrez, Chiapas, Mexico.

Chandler, R.B. \& Royle, J.A. (2013) Spatially explicit models for inference about density in unmarked or partially marked populations. Annals of Applied Statistics, 7, 936-954.

CONABIO (2020) Sistema Nacional de Información sobre Biodiversidad de México. Comisión Nacional para el Conocimiento y Uso de la Biodiversidad. Secretaría de Medio Ambiente y Recursos Naturales. snib.mx [accessed 20 August 2003]. 
Cove, M.V., Vargas, L.E.P., De la Cruz, J.C., Spínola, R.M., JACKson, V.L., SAÉnZ, J.C. \& Chassot, O. (2013) Factors influencing the occurrence of the Endangered Baird's tapir Tapirus bairdii: potential flagship species for a Costa Rican biological corridor. Oryx, 48, 402-409.

Cusack, J.J., Swanson, A., Coulson, T., Packer, C., Carbone, C., Dickman, A.J. et al. (2015) Applying a random encounter model to estimate lion density from camera traps in Serengeti National Park, Tanzania. Journal of Wildlife Management, 79, 1014-1021.

de la Torre, J.A., Rivero, M., Camacho, G. \& ÁlvarezMÁrqueZ, L.A. (2018) Assessing occupancy and habitat connectivity for Baird's tapir to establish conservation priorities in the Sierra Madre de Chiapas, Mexico. Journal for Nature Conservation, 41, 16-25.

EFFord, M.G. (2020) secr: Spatially Explicit Capture-Recapture Models. R package. Version 4.2.2. otago.ac.nz/density/SECRinR. html [accessed 20 January 2021].

Efford, M.G., Borchers, D.L. \& Byrom, A.E. (2009) Density estimation by spatially capture-recapture: likelihood based methods. In Modeling Demographic Processes in Marked Populations (eds D.L. Thomson, E.G. Cooch \& M.J. Conroy), pp. 255-269. Springer, Berlin, Germany.

Fiske, I., Chandler, R., Miller, D., Royle, A., Kery, M., Hostetler, J. \& Hutchinson, R. (2011) Unmarked: an R package for fitting hierarchical models of wildlife occurrence and abundance. Journal of Statistical Software, 1-23.

Foerster, C.R. \& Vaughan, C. (2002) Home range, habitat use, and activity of Baird's Tapir in Costa Rica. Biotropica, 34, 423-437.

Foster, R.J. \& Harmsen, B.J. (2012) A critique of density estimation from camera-trap data. Journal of Wildlife Management, 76, 224-236.

García, M., Jordan, C., O'Farril, G., Poot, C., Meyer, N., Estrada, N. et al. (2016) Tapirus bairdii. In The IUCN Red List of Threatened Species 2016. dx.doi.org/10.2305/IUCN.UK.2016-1.RLTS. T21471A45173340.en [accessed 20 January 2021].

González-Maya, J.F., Schipper, J., Polidoro, B., Hoepker, A., Zarrate-Charry, D. \& Belant, J.L. (2012) Baird's tapir density in high elevation forests of the Talamanca region of Costa Rica. Integrative Zoology, 7, 381-388.

Janis, C. (1984) Tapirs as living fossils. In Living Fossils (eds N. Eldredge \& S.M. Stanley), p. 8o-86. Springer-Verlag, New York, USA.

Jordan, C.A. (2015) The dynamics of wildlife and environmental knowledge in a bioculturally diverse coupled natural and human system in the Caribbean region of Nicaragua. $\mathrm{PhD}$ thesis, Michigan State University, East Lansing, USA.

Jordan, C.A., Hoover, B., Dans, A.J., Schank, C. \& Miller, J.A. (2019) The impact of hurricane Otto on Baird's Tapir movement in Nicaragua's Indio Maíz Biological Reserve. In Movement Ecology of Neotropical Forest Mammals (eds R. Reyna-Hurtado \& C. Chapman), pp. 5-19. Springer, New York, USA.

Kane, M.D., Morin, D.J. \& Kelly, M.J. (2015) Potential for camera-traps and spatial mark-resight models to improve monitoring of the Critically Endangered West African lion (Panthera leo). Biodiversity and Conservation, 24, 3527-3541.

Lavariega-Nolasco, M.C., Briones-Salas, M., MazasTeodocio, A. \& Durán-Medina, E. (2016) Ecology and local knowledge of the Baird's tapir (Tapirella bairdii) in the Sierra Madre de Oaxaca, Mexico. Integrative Zoology, 11, 361-374.

Liu, C., Berry, P.M., Dawson, T.P. \& Pearson, R.G. (2005) Selecting thresholds of occurrence in the prediction of species distributions. Ecography, 3, 385-393.

Lizcano, B.D.J. \& Cavelier, J. (2004) Using GPS collars to study mountain tapirs (Tapirus pinchaque) in the Central Andes of Colombia. Tapir Conservation, 13, 18-23.
MacKenzie, D.I., Nichols, J.D., Royle, J.A., Pollock, K.H., BAiley, L.L. \& Hines, J.E. (2006) Occupancy Estimation and Modeling: Inferring Patterns and Dynamics of Species Occurrence. Academic Press \& Elsevier, Burlington, USA.

Manel, S., Williams, C.H. \& Ormerod, S.J. (2001) Evaluating presence - absence models in ecology: the need to account for prevalence. Journal of Applied Ecology, 38, 921-931.

Mejía-Correa, S., Diaz-Martinez, A. \& Molina, R. (2010) Densidad y hábitos alimentarios de la danta Tapirus bairdii en el Parque Nacional Natural Los Katios, Colombia. Tapir Conservation, 23, 16-23.

Naranjo, E.P. (2009) Ecology and conservation of Baird's tapir in Mexico. Tropical Conservation Science, 4, 140-158.

Noss, A.J., Gardner, B., Maffei, L., Cuéllar, E., Montaño, R., Romero-Muñoz, A. et al. (2012) Comparison of density estimation methods for mammal populations with camera traps in the Kaa-Iya del Gran Chaco landscape. Animal Conservation, 15, 527-535.

O'Connell, A.F., Nichols, J.D. \& Karanth, K.U. (2011) Camera Traps in Animal Ecology: Methods and Analyses. Springer, Tokyo, Japan.

O’Farrill, G., Galetti, M. \& Campos-Arceiz, A. (2013) Frugivory and seed dispersal by tapirs: an insight on their ecological role. Integrative Zoology, 8, 4-17.

Pearce, J. \& Ferrier, S. (200o) Evaluating the predictive performance of habitat models developed using logistic regresion. Ecological Modelling, 225-245.

R Core Team (2018) R: A Language and Environment for Statistical Computing. R Foundation for Statistical Computing, Vienna, Austria.

Rich, L.N., Kelly, M.J., Sollmann, R., Noss, A.J., Maffei, L., ARISPE, R.L. et al. (2014) Comparing capture-recapture, markresight, and spatial mark-resight models for estimating puma densities via camera traps. Journal of Mammalogy, 95, 382-391.

Robin, X., Turck, N., Hainard, A., Tiberti, N., Lisacek, F., SANCHEZ, J.-C. et al. (2011) pROC: an open-source package for $R$ and $S+$ to analyze and compare ROC curves. BMC Bioinformatics, $12,1-8$.

RowCLIFFe, J.M. (2019) camtools: Processing of tagged camera images to generate and map trap rates, create detection matrices for occupancy analyses, and estimate density using REM. GitHub repository. Version 1.o. github.com/MarcusRowcliffe/camtools [accessed 20 January 2021].

Rowcliffe, J.M., Field, J., Turvey, S.T. \& Carbone, C. (2008) Estimating animal density using camera traps without the need for individual recognition. Journal of Applied Ecology, 45, 1228-1236.

Royle, J.A., Chandler, R.B., Sollmann, R. \& Gardner, B. (2014) Spatial Capture-Recapture. Elsevier, Amsterdam, The Netherlands.

Schank, C., Cove, M.V., Kelly, M.J., Mendoza, E., O’Farrill, G., REYNA-HuRTADo, R. et al. (2017) Using a novel model approach to assess the distribution and conservation status of the Endangered Baird's tapir. Diversity and Distributions, 23, 1459-1471.

Schank, C., Arima, E.Y., Cove, M.V., Brandt, L.S.E., BrenesMora, E., Carver, A. et al. (2020) Population status, connectivity, and conservation action for the Endangered Baird's tapir. Biological Conservation, 245, 108501

Sollmann, R., Gardner, B., Chandler, R.B., Shindle, D.B., Onorato, D.P., Royle, J.A. \& O'Connell, A.F. (2013) Using multiple data sources provides density estimates for Endangered Florida panther. Journal of Applied Ecology, 50, 961-968.

Tobler, M. (2002) Habitat use and diet of Baird's tapirs (Tapirus bairdii) in a montane cloud forest of the Cordillera de Talamanca, Costa Rica. Biotropica, 34, 468-474.

Tobler, M. (2008) The ecology of the lowland tapir in Madre De Dios, Peru: using new technologies to study large rainforest mammals. $\mathrm{PhD}$ thesis, Texas A\&M University, College Station, USA. 
Tobler, M., Hibert, F., Debeir, L. \& Richard-Hansen, C. (2013) Estimates of density and sustainable harvest of the lowland tapir Tapirus terrestris in the Amazon of French Guiana using a Bayesian spatially explicit capture-recapture model. Oryx, 48, 410-419.

Tobler, M. \& Powell, G.V.N. (2013) Estimating jaguar densities with camera traps: problems with current designs and recommendations for future studies. Biological Conservation, 159, 109-118.
White, G.C., Anderson, D.R., Burnham, K.P. \& Otis, D.L. (1982) Capture-Recapture and Removal Methods for Sampling Closed Populations. Los Alamos National Laboratory, Los Alamos, USA. Zero, V.H., Sundaresan, S.R., O’Brien, T.G. \& Kinnaird, M.F. (2013) Monitoring an Endangered savannah ungulate, Grevy's zebra Equus grevyi: choosing a method for estimating population densities. Oryx, 47, 410-419. 